\title{
Phase I trial to investigate the effect of renal impairment on isavuconazole pharmacokinetics
}

\author{
Robert W. Townsend ${ }^{1} \cdot$ Shahzad Akhtar $^{1} \cdot$ Harry Alcorn $^{2} \cdot$ Jolene K. Berg $^{2}$ • \\ Donna L. Kowalski ${ }^{1} \cdot$ Salim Mujais ${ }^{1} \cdot$ Amit V. Desai $^{1}$
}

Received: 14 October 2016 / Accepted: 1 February 2017 / Published online: 7 March 2017

(C) The Author(s) 2017. This article is published with open access at Springerlink.com

\begin{abstract}
Purpose The purpose of the study is to evaluate the effect of renal impairment (RI) and end-stage renal disease (ESRD) on the pharmacokinetics (PK) of isavuconazole and the inactive cleavage product, BAL8728.

Methods A single intravenous dose of the prodrug isavuconazonium sulfate ( $372 \mathrm{mg}$, equivalent to $200 \mathrm{mg}$ isavuconazole and $75 \mathrm{mg}$ of BAL8728 cleavage product) was administered to healthy controls (parts 1 and 2) and participants with mild, moderate, or severe RI (part 2) or ESRD (part 1); ESRD participants received two doses of $200 \mathrm{mg}$ isavuconazole, $1 \mathrm{~h}$ post-dialysis (day 1 ) and prior to dialysis (day 15). Plasma PK parameters for isavuconazole included maximum concentration $\left(C_{\max }\right)$, area under the concentration-time curve (AUC) from time of dose to $72 \mathrm{~h}\left(\mathrm{AUC}_{72}\right)$, AUC extrapolated to infinity $\left(\mathrm{AUC}_{\infty}\right)$, AUC to last measurable concentration $\left(\mathrm{AUC}_{\text {last }}\right)$, half-life $\left(t_{1 / 2} \mathrm{~h}\right)$, volume of distribution $\left(V_{\mathrm{z}}\right)$, and total clearance $(\mathrm{CL})$, for the healthy control group versus those with mild, moderate, or severe RI or ESRD.

Results Isavuconazole $C_{\max }$ values were $4 \%$ higher in mild RI and 7,14 , and $21 \%$ lower in participants with moderate RI,
\end{abstract}

Shahzad Akhtar's affiliation at the time of the study.

Electronic supplementary material The online version of this article (doi:10.1007/s00228-017-2213-7) contains supplementary material, which is available to authorized users.

Robert W. Townsend

Robert.Townsend@astellas.com

1 Global Clinical Pharmacology and Exploratory Development Science, Astellas Pharma Global Development, Inc., 1 Astellas Way, Northbrook, IL 60062, USA

2 DaVita Clinical Research, Minneapolis, MN, USA severe RI, or ESRD versus the healthy control group, respectively. When hemodialysis occurred post-dose (day 15), participants with ESRD had a $30 \%$ increase in $\mathrm{AUC}_{72}$ for isavuconazole in parallel with reduction of extracellular volume induced by dialysis. Exposure $\left(\mathrm{AUC}_{\infty}\right.$ and $\left.\mathrm{AUC}_{\text {last }}\right)$ was not significantly different for participants with mild, moderate, or severe RI versus healthy controls although there was considerable variability. The $\mathrm{t}_{1 / 2}$ (day 1 ) was $125.5 \pm 63.6 \mathrm{~h}$ (healthy control group), $204.5 \pm 82.6 \mathrm{~h}$ (ESRD group) in part 1 , and $140.5 \pm 77.7 \mathrm{~h}$ (healthy control group), $117.0 \pm 66.2 \mathrm{~h}$ (mild RI), $158.5 \pm 56.4 \mathrm{~h}$ (moderate RI), and $145.8 \pm 65.8 \mathrm{~L} / \mathrm{h}$ (severe RI) in part 2. CL was $2.4 \pm 0.8 \mathrm{~L} / \mathrm{h}$ (healthy control group) and $2.9 \pm 1.3 \mathrm{~L} / \mathrm{h}$ (ESRD group) in part 1 and $2.4 \pm 1.2$ $\mathrm{L} / \mathrm{h}$ (healthy control group), $2.5 \pm 1.0 \mathrm{~L} / \mathrm{h}$ (mild RI), $2.2 \pm 0.8 \mathrm{~L} / \mathrm{h}$ (moderate RI), and $2.4 \pm 0.8 \mathrm{~L} / \mathrm{h}$ (severe RI) in part 2 . The $V_{\mathrm{z}}$ was $382.6 \pm 150.6 \mathrm{~L}$ in the healthy control group and $735.6 \pm 277.3 \mathrm{~L}$ in ESRD patients on day 1 in part 1 of the study. In part 2 of the study, $V_{\mathrm{z}}$ was $410.8 \pm 89.7 \mathrm{~L}$ in the healthy control group, $341.6 \pm 72.3 \mathrm{~L}$ in mild RI, $509.1 \pm 262.2 \mathrm{~L}$ in moderate RI, and $439.4 \mathrm{~L}$ in severe RI.

Conclusions Based on the findings of this study, dose adjustments of isavuconazole are unlikely to be required in individuals with RI or in those with ESRD who receive hemodialysis.

Keywords End-stage renal disease $\cdot$ Isavuconazole · Pharmacokinetics $\cdot$ Renal impairment

\section{Introduction}

Invasive fungal diseases (IFD), predominantly aspergillosis, are a prevalent cause of morbidity and mortality in immunocompromised patients, such as those with hematological malignancies or those undergoing transplantation [1-4]. Renal impairment (RI) is an independent risk factor for mortality in both hematopoietic 
stem cell transplant and solid organ transplant patients with invasive aspergillosis (IA) [5]. In intensive care units, $43 \%$ of patients with IA infections experience acute renal failure, which contributes to the mortality associated with IA [6]. The renal excretion of drugs and/or their metabolites may be hindered in patients with RI, and this could lead to an excessive accumulation of the drug in the body [7]. Conversely, hemodialysis may result in removal of some drugs, and thereby, additional doses may be required to prevent underdosing [8]. Triazole antifungal agents are pivotal in the treatment of IA [9]; however, their use may be restricted in patients with RI $[10,11]$. Voriconazole and posaconazole may have restricted use in patients with moderate-to-severe RI due to the accumulation of the vehicle cyclodextrin used in their intravenous (IV) formulations [10-12]. Caution is also recommended for the use of itraconazole in patients with RI due to limited data on the use of this drug in this patient population [13]. Therefore, there is a requirement for potent antifungal agents that are efficacious and well tolerated to combat IFD in patients with RI.

Isavuconazonium sulfate is a water-soluble prodrug of the novel, broad-spectrum, triazole antifungal agent isavuconazole, which was developed to facilitate IV administration without the need for nephrotoxic excipients $[14,15]$. Isavuconazonium sulfate is rapidly converted in plasma to the active triazole isavuconazole and the inactive cleavage product BAL8728. The per-oral (PO) capsules and cyclodextrin-free IV formulations of the prodrug are approved for the primary treatment of adults with IA and invasive mucormycosis by the US Food and Drug Administration (FDA) [16]. Isavuconazole is also approved by the European Medicines Agency (EMA) for the treatment of IA and treatment of invasive mucormycosis when amphotericin B is inappropriate [17].

A formal renal study using the final formulation, isavuconazonium sulfate, was conducted in accordance with the FDA and the EMA guidance on the evaluation of the pharmacokinetics (PK) of medicines in patients with impaired renal function $[18,19]$. The objective of this study was to evaluate the effect of RI (mild, moderate, or severe) and end-stage renal disease (ESRD) on the PK of isavuconazole compared with the PK in healthy participants with normal renal function.

\section{Methods}

\section{Study design}

This was a phase I, open-label, single-dose parallel group study in male and female participants conducted in two parts (ClinicalTrials.gov NCT01555866 covering parts 1 and 2). Part 1 was a single-center study of isavuconazole administered to healthy participants with renal function in the normal range (referred to as the healthy control group) and those with ESRD requiring dialysis. Part 2 was a multi-center study of isavuconazole administered to a healthy control group and those with mild, moderate, or severe RI.

Both parts of the study were conducted in accordance with the Declaration of Helsinki and the International Conference on Harmonisation Guidelines for Good Clinical Practice. For all sites, approval of the protocol (9766-CL-0018) was obtained from the governmental authorities and Institutional Review Board(s).

\section{Eligibility}

Male and female participants aged $18-65$ years, weighing $\geq 45 \mathrm{~kg}$, and with a body mass index of $18-35 \mathrm{~kg} / \mathrm{m}^{2}$ were enrolled. At screening, RI was based on the Cockcroft-Gault (CG) formula and adjusted for body surface area (BSA), then grouped as healthy control group (creatinine clearance $\left(\mathrm{CL}_{\mathrm{cr}}\right)>80 \mathrm{~mL} / \mathrm{min} / 1.73 \mathrm{~m}^{2}$ ), participants with ESRD and requiring hemodialysis $\left(\mathrm{CL}_{\mathrm{cr}}<15 \mathrm{~mL} / \mathrm{min} / 1.73 \mathrm{~m}^{2}\right)$, and participants with RI: mild $\left(\mathrm{CL}_{\mathrm{cr}} 50-80 \mathrm{~mL} / \mathrm{min} / 1.73 \mathrm{~m}^{2}\right)$, moderate $\left(\mathrm{CL}_{\mathrm{cr}} 30\right.$ $\left.<50 \mathrm{~mL} / \mathrm{min} / 1.73 \mathrm{~m}^{2}\right)$, and severe $\mathrm{CL}_{\mathrm{cr}}(<30 \mathrm{~mL} / \mathrm{min} /$ $1.73 \mathrm{~m}^{2}$ ). Participants were selected by age, sex, weight, and smoking status so that the ranges were similar between the healthy control group and each of the groups with RI.

\section{Assessments}

Each participant in part 1 and part 2 of the study received a single 1-h IV infusion of isavuconazonium sulfate $372 \mathrm{mg}$ (equivalent to $200 \mathrm{mg}$ isavuconazole) on day 1 (approximately $1 \mathrm{~h}$ after completion of their routine hemodialysis procedure in participants with ESRD). Participants with ESRD in part 1 of the study received an additional dose just prior to dialysis on day 15 .

Blood samples for isavuconazole and BAL8728 plasma concentrations were collected pre-dose to $72 \mathrm{~h}$ post-dose on days 1 and 15 for ESRD participants and pre-dose to $72 \mathrm{~h}$ post-dose on day 1 for the healthy control group and RI participants. Single blood samples were taken from ESRD and RI participants on days 6, 8, 11, 13, and 15. During dialysis, samples were collected simultaneously at the inlet and outlet sides of the dialyzer as well as from the dialysate. For all participants, an additional blood sample was obtained at $4 \mathrm{~h}$ post-dose on day 1 for analysis of isavuconazole fraction unbound ( $\mathrm{fu})$. 
In participants who produced urine, samples for the bioanalysis of isavuconazole and BAL8728 were collected up to $72 \mathrm{~h}$ post-dose on day 1. Renal function was assessed using the CG method adjusted for BSA using the following formula:

$$
\begin{aligned}
& \mathrm{CL}_{\mathrm{cr}}\left(\mathrm{mL} / \mathrm{min} / 1.73^{2}\right) \\
& =\frac{[140-\text { age }(\text { years })] \times \text { actual weight }(\mathrm{kg}) \times 0.85 \text { for females } \times 1.73}{72 \times \mathrm{S}_{\mathrm{cr}}(\mathrm{mg} / \mathrm{dL}) \times \mathrm{BSA}}
\end{aligned}
$$

where $S_{\text {cr }}$ is serum creatinine.

Estimated glomerular filtration rate (eGFR) using the abbreviated Modification of Diet in Renal Disease (MDRD) formula was calculated using the following formula:

$$
\begin{aligned}
& \text { eGFR-MDRD mL/min } / 1.73 \mathrm{~m}^{2} \\
& =175 \times \mathrm{S}_{\mathrm{cr}}{ }^{-1.154} \times \mathrm{age}^{-0.203} \times(0.742 \text { if female }) \\
& \quad \times(1.212 \text { if African American })
\end{aligned}
$$

\section{Pharmacokinetic assessments}

Due to the extensive protein binding of isavuconazole to plasma proteins, the PK parameters reported in this study were based on total isavuconazole concentrations in plasma. Plasma PK sampling time points included pre-dose (prior to start of infusion), upon completion of infusion (obtained $1 \mathrm{~min}$ prior to end of infusion), $1.5,2,3,4,5,6,8,12,24$ (day 2), 36 (day 2), 48 (day 3), 72 (day 4), 120 (day 6), 168 (day 8), 240 (day 11), 288 (day 13), 336 (day 15) h after the start of infusion. The primary plasma PK parameters for isavuconazole were area under the concentration-time curve (AUC) from time of dosing to $72 \mathrm{~h}\left(\mathrm{AUC}_{72}\right)$ and maximum concentration $\left(C_{\max }\right)$ for the healthy control group compared with participants with ESRD, AUC from time of dosing extrapolated to infinity $\left(\mathrm{AUC}_{\infty}\right)$, $\mathrm{AUC}$ from time of dosing to last measurable plasma concentration $\left(\mathrm{AUC}_{\text {last }}\right)$, and $C_{\max }$ for the healthy control group compared with participants with mild, moderate, or severe RI. Additional PK parameters for isavuconazole included time to reach $C_{\max }\left(t_{\max }\right)$, total clearance (CL), halflife $\left(t_{1 / 2}\right)$, and volume of distribution $\left(V_{\mathrm{z}}\right)$. PK parameters for BAL8728 included: healthy, ESRD, and RI participants (day 1): $\mathrm{AUC}_{\infty}, \mathrm{AUC}_{72}, \mathrm{AUC}_{\text {last }}, C_{\max }, t_{\max }, t_{1 / 2}$, $V_{\mathrm{z}}$, and CL: ESRD participants (day 15): $\mathrm{AUC}_{72}, C_{\max }$, and $t_{\max }$.

Urine was collected for all able subjects over the following time intervals: day 1 pre-dose ( -2 to 0 ) $0-6$, $6-12,12-24,24-48$, and $48-72 \mathrm{~h}$ after start of infusion. PK parameters included the amount and percentage of drug excreted unchanged in the urine $\left(\mathrm{Ae}_{\text {last }} / \mathrm{Ae}_{72}\right.$, for the dialysis comparisons) for all participants and renal clearance $\left(\mathrm{CL}_{\mathrm{R}}\right.$ calculated as $\left.\mathrm{Ae}_{\text {last }} / \mathrm{AUC}_{\text {last }}\right)$ at day 1 for the healthy control group and participants with mild, moderate, or severe $\mathrm{RI}$; dialysis clearance $\left(\mathrm{CL}_{\mathrm{D}}\right)$ at day 15 was also assessed for participants with ESRD.

Plasma PK parameters were calculated using WinNonlin ${ }^{\circledR}$ version 5.2 or higher (Certara, Princeton, NJ, USA).

\section{Safety assessments}

Treatment-emergent adverse events (TEAEs; defined as adverse events that started any time after the first dose of study drug was administered through the follow-up visit) were assessed for all participants. The number and percentage of participants with TEAEs were summarized for each renal function group by system organ class.

\section{Statistical analysis}

A sample size of 16 participants ( 8 per group) in part 1 of the study and 32 participants ( 8 per group) in part 2 of the study was determined based on the precedent set by other PK studies similar in design. No formal sample size calculation was performed.

The PK analyses used two approaches: One approach compared PK between each renal impaired group ( $\mathrm{CG}$ method $\mathrm{CL}_{\mathrm{cr}}$ ), and a second approach compared the relationship between PK and eGFR (MDRD method). Descriptive statistics (number of participants, mean, and standard deviation, minimum, median, and maximum) were used to summarize continuous variables. Descriptive statistics used for categorical variables consisted of frequency and percentage of participants in each category. In addition, for PK parameters, geometric mean and coefficient of variation were also determined.

To assess the effect of RI on the PK of isavuconazole and BAL8728, an analysis of covariance (ANCOVA) was performed on natural log-transformed $\mathrm{AUC}_{\infty}, \mathrm{AUC}_{\text {last }}$, and $C_{\max }$ with renal function group (mild, moderate, or severe RI and healthy control group) as a fixed effect and age, sex, and current smoking status as covariates. The effect of time of dialysis relative to dosing on the PK of isavuconazole and BAL8728 was assessed using ANCOVA on the natural log-transformed $\mathrm{AUC}_{72}$ and $C_{\max }$ between day 1 and day 15 (calculated using pre-dialysis access line concentrations), while subjects were on dialysis from the ESRD group with the visit as a fixed effect (day 1 and day 15), the subject as a random effect, and weight on day 1 and day 15 as a covariate. The $90 \%$ confidence intervals (CIs) around the geometric least 
square mean (LSM) ratios (day 15/day 1) of $\mathrm{AUC}_{72}$ and $C_{\max }$ were constructed.

Covariates were assessed at the 0.1 significance level and removed from the model if insignificant. The $90 \%$ CIs around the geometric LSM ratios (severe/healthy control group, moderate/healthy control group, and mild/healthy control group) of $\mathrm{AUC}_{\infty}, \mathrm{AUC}_{\text {last }}$, and $C_{\max }$ were constructed. No effect of RI on PK was declared if the corresponding CIs for the ratio fell completely within the interval $(70 \%, 143 \%)$ for all three parameters of isavuconazole.

Safety data were analyzed using descriptive statistics. All statistical analyses were performed using $\mathrm{SAS}^{\circledR}$ version 9.1 or higher (Statistical Analysis Software, Cary, NC, USA).

\section{Results}

\section{Patient characteristics}

A total of 20 participants were enrolled, and 19 completed part 1 of the study; 29 participants were enrolled and completed part 2 of the study (Table 1). Only five participants were enrolled in the severe RI group due to slow recruitment.

\section{Dialysis and PK of isavuconazole and BAL8728}

Mean plasma concentration-time profiles for isavuconazole in participants with ESRD compared with the healthy control group are shown in Fig. 1. More than $99.9 \%$ of isavuconazole was bound to protein in samples from all treatment groups. On day 1 , when isavuconazonium sulfate was administered as a 1-h IV infusion post-hemodialysis in ESRD participants, there was a $34 \%$ decrease in $\mathrm{AUC}_{72}$ of isavuconazole and a $21 \%$ decrease in $C_{\max }$ compared with the healthy control group dosed under similar conditions (Table 2). BAL8728 $C_{\max }$ values were $2 \%$ lower in participants with ESRD, compared with the healthy control group. The $\mathrm{AUC}_{72}$ for isavuconazole increased by $30 \%$ and the $\mathrm{AUC}_{72}$ for BAL 8728 decreased by $22 \%$ (Table 2) with dosing of isavuconazole prior to dialysis in participants with ESRD. The day 15 result was similar to the $\mathrm{AUC}_{72}$ results obtained for the healthy control group on day 1 (Table 3 ). The mean $t_{1 / 2}$ of total isavuconazole was approximately 1.6-fold longer in participants with ESRD versus the healthy control group (Table 3). Less than $1 \%$ of the administered isavuconazole was recovered in dialysate fluid, consistent with the low dialysis clearance $\left(\mathrm{CL}_{\mathrm{D}}\right)$ of $292 \mathrm{~mL} / \mathrm{h}$.

\section{Isavuconazole and BAL8728 PK in renal impairment}

There were no consistent changes in $t_{1 / 2}$ of isavuconazole or BAL8728 plasma concentrations observed in participants with mild-to-severe RI versus healthy control group (Table 4; Supplementary Table S1). Compared with the healthy control group, plasma BAL8728 $\mathrm{AUC}_{72}$ for subjects with ESRD was $10 \%$ higher, whereas the plasma $\mathrm{AUC}_{\infty}$ in mild, moderate, or severe RI groups were 29, 4, and $24 \%$ higher, respectively. $\mathrm{A}_{\mathrm{e}} \%$ and $\mathrm{CL}_{\mathrm{R}}$ for both isavuconazole and BAL8728 decreased with increasing RI (mild to severe). BAL8728 $C_{\max }$ values in participants with mild and severe RI were 16 and $11 \%$ higher, respectively, and $3 \%$ lower in participants with moderate RI.

Table 1 Demographics and characteristics of participants

\begin{tabular}{|c|c|c|c|c|c|c|}
\hline & \multicolumn{2}{|l|}{ Study part 1} & \multicolumn{4}{|l|}{ Study part 2} \\
\hline & $\begin{array}{l}\text { Healthy control } \\
\text { group }(n=9)\end{array}$ & $\begin{array}{l}\text { ESRD } \\
(n=11)\end{array}$ & $\begin{array}{l}\text { Healthy control } \\
\text { group }(n=8)\end{array}$ & $\begin{array}{l}\text { Mild RI } \\
(n=8)\end{array}$ & $\begin{array}{l}\text { Moderate RI } \\
(n=8)\end{array}$ & $\begin{array}{l}\text { Severe RI } \\
(n=5)\end{array}$ \\
\hline Age [years], median (range) & $48(19-64)$ & $52(20-64)$ & $51(34-57)$ & $63(51-65)$ & $56(34-61)$ & $59(50-62)$ \\
\hline Males, $n(\%)$ & $5(55.6)$ & $5(45.5)$ & $5(62.5)$ & $5(62.5)$ & $3(37.5)$ & $5(100)$ \\
\hline \multicolumn{7}{|l|}{ Race, $n(\%)$} \\
\hline White & $8(88.9)$ & $1(9.1)$ & $6(75.0)$ & $8(100)$ & $4(50.0)$ & $3(60.0)$ \\
\hline Black or African American & 0 & $10(90.9)$ & $2(25.0)$ & 0 & $3(37.5)$ & $2(40.0)$ \\
\hline Other & $1(11.1)$ & 0 & 0 & 0 & $1(12.5)$ & 0 \\
\hline \multicolumn{7}{|l|}{ Ethnicity, $n(\%)$} \\
\hline Not Hispanic or Latino & $9(100)$ & $11(100)$ & $4(50.0)$ & $3(37.5)$ & $5(62.5)$ & $3(60.0)$ \\
\hline eGFR-CG, mean $\pm \mathrm{SD}^{\mathrm{a}}$ & $104.1 \pm 18.6$ & $8.7 \pm 2.3$ & $104.6 \pm 17.9$ & $67.7 \pm 7.7$ & $39.9 \pm 5.7$ & $18.5 \pm 5.4$ \\
\hline eGFR-MDRD, mean $\pm \mathrm{SD}^{\mathrm{b}}$ & $90.7 \pm 9.1$ & $6.6 \pm 1.8$ & $94.7 \pm 19.8$ & $64.1 \pm 12.4$ & $32.1 \pm 5.9$ & $14.8 \pm 5.2$ \\
\hline
\end{tabular}

$C G$ Cockcroft-Gault method, $e G F R$ estimated glomerular filtration rate, ESRD end-stage renal disease, MDRD modification of diet in renal disease, $R I$ renal impairment, $S D$ standard deviation

a eGFR-CG $\left(\mathrm{mL} / \mathrm{min} / 1.73 \mathrm{~m}^{2}\right) \times$ Body surface area/1.73

b eGFR-MDRD (mL/min/1.73 $\left.\mathrm{m}^{2}\right)$ 
Fig. 1 Mean (standard deviation [SD]) plasma concentration-time profiles for isavuconazole in a healthy control group (day 1) versus participants with end-stage renal disease on both day 1 and day 15 and $\mathbf{b}$ for participants with mild, moderate, and severe RI versus the healthy control group
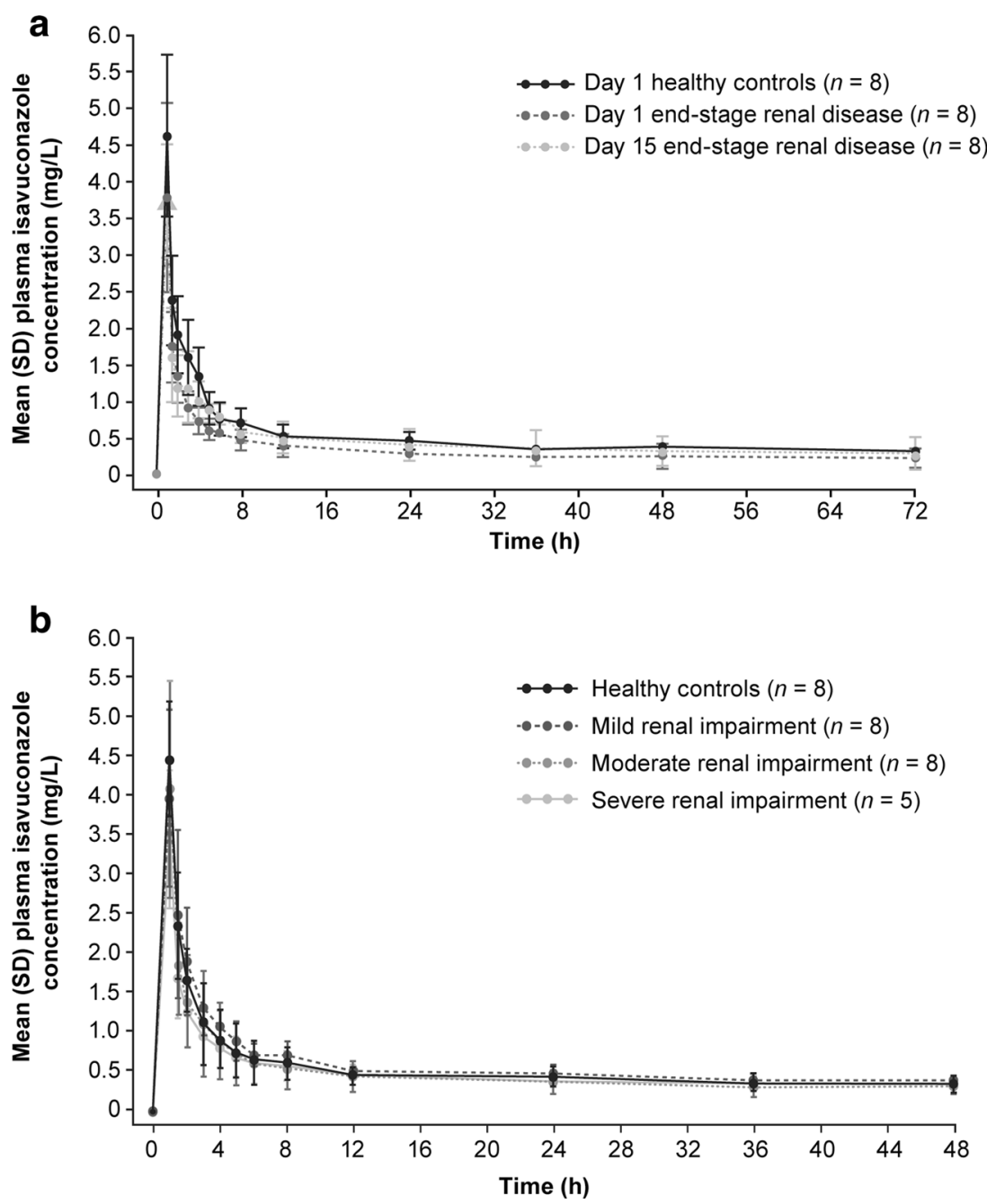

There was no significant relationship between total plasma isavuconazole $\mathrm{PK}$ parameters $\left(C_{\max }\right.$ and $\left.\mathrm{CL}\right)$ with continuous markers of renal function $\mathrm{CL}_{\mathrm{cr}}$ and eGFR using either the $\mathrm{CG}$ or the abbreviated MDRD formula (Fig. 2, Supplementary Fig. S1). No correlation was identified between BAL8728 PK parameters and markers of renal function (data not shown).
Table 2 Geometric LSM ratios for isavuconazole and BAL 8728 in patients with ESRD versus healthy controls and for ESRD at day 15 versus day 1

\begin{tabular}{|c|c|c|c|}
\hline Parameter & Ratio study group/study group & $\begin{array}{l}\text { Geometric LSM } \\
\text { ratio \% }\end{array}$ & $90 \% \mathrm{CI}$ \\
\hline \multicolumn{4}{|c|}{ Isavuconazole } \\
\hline $\mathrm{AUC}_{72}$ & ESRD/healthy controls & 66.3 & $50.8-86.7$ \\
\hline$C_{\max }$ & ESRD/healthy controls & 79.3 & $60.6-103.9$ \\
\hline $\mathrm{AUC}_{72}$ & ESRD day $15 /$ ESRD day 1 & 130.5 & $122.8-138.6$ \\
\hline \multicolumn{4}{|l|}{ BAL8728 } \\
\hline $\mathrm{AUC}_{72}$ & ESRD/healthy controls & 110.3 & $85.4-142.4$ \\
\hline$C_{\max }$ & ESRD/healthy controls & 97.7 & $76.0-125.7$ \\
\hline $\mathrm{AUC}_{72}$ & ESRD day $15 /$ ESRD day 1 & 78.2 & $68.6-89.0$ \\
\hline
\end{tabular}

$A U C_{72}$ area under the concentration curve at $72 \mathrm{~h}, \mathrm{CI}$ confidence intervals, $C_{\max }$ maximum plasma concentration, $E S R D$ end-stage renal disease, $L S M$ least square mean 
Table 3 Isavuconazole and BAL8728 pharmacokinetic parameters for participants with ESRD and healthy control group

\begin{tabular}{|c|c|c|c|c|c|c|}
\hline \multirow[t]{2}{*}{ Parameter } & \multicolumn{3}{|l|}{ Isavuconazole } & \multicolumn{3}{|l|}{ BAL8728 } \\
\hline & $\begin{array}{l}\text { Healthy control } \\
\text { group }(n=8)^{\mathrm{a}}\end{array}$ & $\begin{array}{l}\text { ESRD day } 1 \\
(n=8)^{\mathrm{b}}\end{array}$ & $\begin{array}{l}\text { ESRD day } 15 \\
(n=8)\end{array}$ & $\begin{array}{l}\text { Healthy control } \\
\text { group }(n=8)^{\mathrm{a}}\end{array}$ & $\begin{array}{l}\text { ESRD day } 1 \\
(n=8)^{\mathrm{b}}\end{array}$ & $\begin{array}{l}\text { ESRD day } 15 \\
(n=8)\end{array}$ \\
\hline $\mathrm{AUC}_{72}, \mathrm{mg} * \mathrm{~h} / \mathrm{L}$ & $36.9 \pm 9.5$ & $25.1 \pm 10.0$ & $32.3 \pm 15.4$ & $1.2 \pm 0.4$ & $1.3 \pm 0.3$ & $0.9 \pm 0.2$ \\
\hline$C_{\max }, \mathrm{mg} / \mathrm{L}$ & $4.6 \pm 1.1$ & $3.7 \pm 1.3$ & $3.7 \pm 0.8$ & $0.9 \pm 0.2$ & $0.9 \pm 0.3$ & $0.9 \pm 0.2$ \\
\hline $\mathrm{AUC}_{\infty}, \mathrm{mg} * \mathrm{~h} / \mathrm{L}$ & $94.7 \pm 32.3$ & $95.7 \pm 78.6$ & - & $1.2 \pm 0.4$ & $1.3 \pm 0.3$ & - \\
\hline $\mathrm{AUC}_{\text {last }}, \mathrm{mg} * \mathrm{~h} / \mathrm{L}$ & $77.9 \pm 22.1$ & $62.0 \pm 40.2$ & - & $1.1 \pm 0.3$ & $1.2 \pm 0.3$ & - \\
\hline$t_{\max }, \mathrm{h}$ & $1.0(1.0-1.1)$ & $1.0(1.0-1.0)$ & $1.0(1.0-1.0)$ & $1.0(1.0-1.1)$ & $1.0(1.0-1.0)$ & $1.0(1.0-1.0)$ \\
\hline$t_{1 / 2}, \mathrm{~h}$ & $125.5 \pm 63.3$ & $204.5 \pm 82.6$ & - & $1.3 \pm 0.1$ & $1.5 \pm 0.3$ & - \\
\hline$V_{\mathrm{z}}, \mathrm{L}$ & $386.2 \pm 150.5$ & $735.6 \pm 277.3$ & - & $133.3 \pm 35.2$ & $144.3 \pm 64.3$ & - \\
\hline $\mathrm{CL}, \mathrm{L} / \mathrm{h}$ & $2.4 \pm 0.8$ & $2.9 \pm 1.3$ & - & $70.5 \pm 23.0$ & $64.5 \pm 23.9$ & - \\
\hline $\mathrm{Ae}_{\text {last }}, \%$ & $0.5 \pm 0.2$ & - & - & - & - & - \\
\hline $\mathrm{CL}_{\mathrm{R}}, \mathrm{mL} / \mathrm{h}$ & $12.5 \pm 5.5$ & - & - & - & - & - \\
\hline $\mathrm{CL}_{\mathrm{D}}, \mathrm{mL} / \mathrm{h}$ & - & $291.7 \pm 87.4$ & - & - & - & - \\
\hline
\end{tabular}

All PK data expressed as mean \pm standard deviation, except $t_{\max }$, which is expressed as median (range)

$A e_{\text {last }}$ cumulative amount of unchanged isavuconazole excreted in the urine, $A U C$ area under the concentration-time curve, $A U C_{72} \mathrm{AUC}$ from time of dosing until $72 \mathrm{~h}, A U C_{\infty}$ AUC extrapolated to infinity, $A U C_{\text {last }}$ AUC to last measurable plasma concentration, $C_{\max }$ maximum concentration of isavuconazole, $C L$ total clearance of isavuconazole, $C L_{D}$ dialysis clearance of isavuconazole, $C L_{R}$ renal clearance of isavuconazole from plasma, ESRD end-stage renal disease, $t_{\max }$ time to reach maximum concentration, $t_{1 / 2}$ half-life of isavuconazole

${ }^{\text {a }}$ One participant discontinued on day 1

${ }^{\mathrm{b}}$ Pharmacokinetic results for three participants with ESRD were unavailable due to a handling error during sample collection resulting in the contamination of $C_{\max }$ values

\section{Urinary excretion}

Isavuconazole urinary clearance decreased in parallel with a decrease in renal function (Supplementary Table S2). The amount of isavuconazole excreted unchanged in urine samples was $0.07 \%$ of the total dose in patients with severe RI compared with $0.44 \%$ in the healthy control group. The small volume of the dialysis clearance in participants with ESRD was consistent with the highly albumin-bound nature of isavuconazole (Supplementary Table S2). BAL8728 was not detected in dialysate samples.

\section{Safety}

Most TEAEs were considered mild. No participant experienced a TEAE that was considered severe, and no deaths were reported during the course of the study. However, one healthy participant in part 1 of the study experienced a TEAE
Table 4 Isavuconazole pharmacokinetic parameters for day 1 for healthy participants compared with individuals with renal impairment

\begin{tabular}{lllll}
\hline Parameter & $\begin{array}{l}\text { Healthy control } \\
\text { group }(n=8)\end{array}$ & $\begin{array}{l}\text { Mild RI } \\
(n=8)\end{array}$ & $\begin{array}{l}\text { Moderate RI } \\
(n=8)\end{array}$ & $\begin{array}{l}\text { Severe RI } \\
(n=5)\end{array}$ \\
\hline $\mathrm{AUC}_{\infty}, \mathrm{mg}^{*} \mathrm{~h} / \mathrm{L}$ & $98.8 \pm 50.5$ & $96.2 \pm 46.9$ & $97.2 \pm 26.3$ & $98.8 \pm 53.9$ \\
$\mathrm{AUC}_{\text {last }}, \mathrm{mg} / \mathrm{h} / \mathrm{L}$ & $75.8 \pm 22.9$ & $77.0 \pm 22.8$ & $74.0 \pm 20.1$ & $73.6 \pm 19.9$ \\
$t_{\max }, \mathrm{h}$ & $1.0(1.0-1.0)$ & $1.0(1.0-1.0)$ & $1.0(1.0-1.0)$ & $1.0(1.0-1.0)$ \\
$t_{1 / 2}, \mathrm{~h}$ & $140.5 \pm 77.7$ & $117.0 \pm 66.2$ & $158.5 \pm 56.4$ & $145.8 \pm 65.8$ \\
$C_{\max }, \mathrm{mg} / \mathrm{L}$ & $4.4 \pm 0.7$ & $3.9 \pm 1.1$ & $4.1 \pm 1.4$ & $3.4 \pm 0.9$ \\
$\mathrm{CL}, \mathrm{L} / \mathrm{h}$ & $2.4 \pm 1.2$ & $2.5 \pm 1.0$ & $2.2 \pm 0.8$ & $2.4 \pm 0.8$ \\
$\mathrm{Ae}_{\text {last }}, \%$ & $0.4 \pm 0.2$ & $0.2 \pm 0.1$ & $0.1 \pm 0.1$ & $0.1 \pm 0.03$ \\
$\mathrm{CL}_{\mathrm{R}}, \mathrm{mL} / \mathrm{h}$ & $14.0 \pm 13.3$ & $6.8 \pm 4.3$ & $3.4 \pm 2.7$ & $2.0 \pm 0.9$ \\
$V_{\mathrm{z}}, \mathrm{L}$ & $410.8 \pm 89.7$ & $341.6 \pm 72.3$ & $509.1 \pm 262.2$ & $439.4 \pm 65.4$ \\
\hline
\end{tabular}

All data are expressed as mean \pm standard deviation, except $t_{\max }$ which is expressed as median (range)

$A e_{\text {last }}$ cumulative amount of unchanged isavuconazole excreted in the urine, $A U C$ area under the concentrationtime curve, $A U C_{72}$ AUC from time of dosing until $72 \mathrm{~h}, A U C_{\infty}$ AUC extrapolated to infinity, $A U C_{\text {last }}$ AUC to last measurable plasma concentration, $C L$ total clearance of isavuconazole, $C L_{R}$ renal clearance of isavuconazole from plasma, $R I$ renal impairment, $t_{\max }$ time to reach maximum concentration, $t_{1 / 2}$, half-life of isavuconazole, $V_{z}$ volume of distribution 
Fig. 2 The relationship between total clearance of isavuconazole (CL) and renal function in relation to creatinine clearance $\left(\mathrm{CL}_{\mathrm{cr}}\right)$ by Cockcroft-Gault (CG) method

(a) and estimated glomerular filtration rate (eGFR) by the Modification of Diet in Renal Disease (MDRD) method (b). $C I$ as confidence intervals
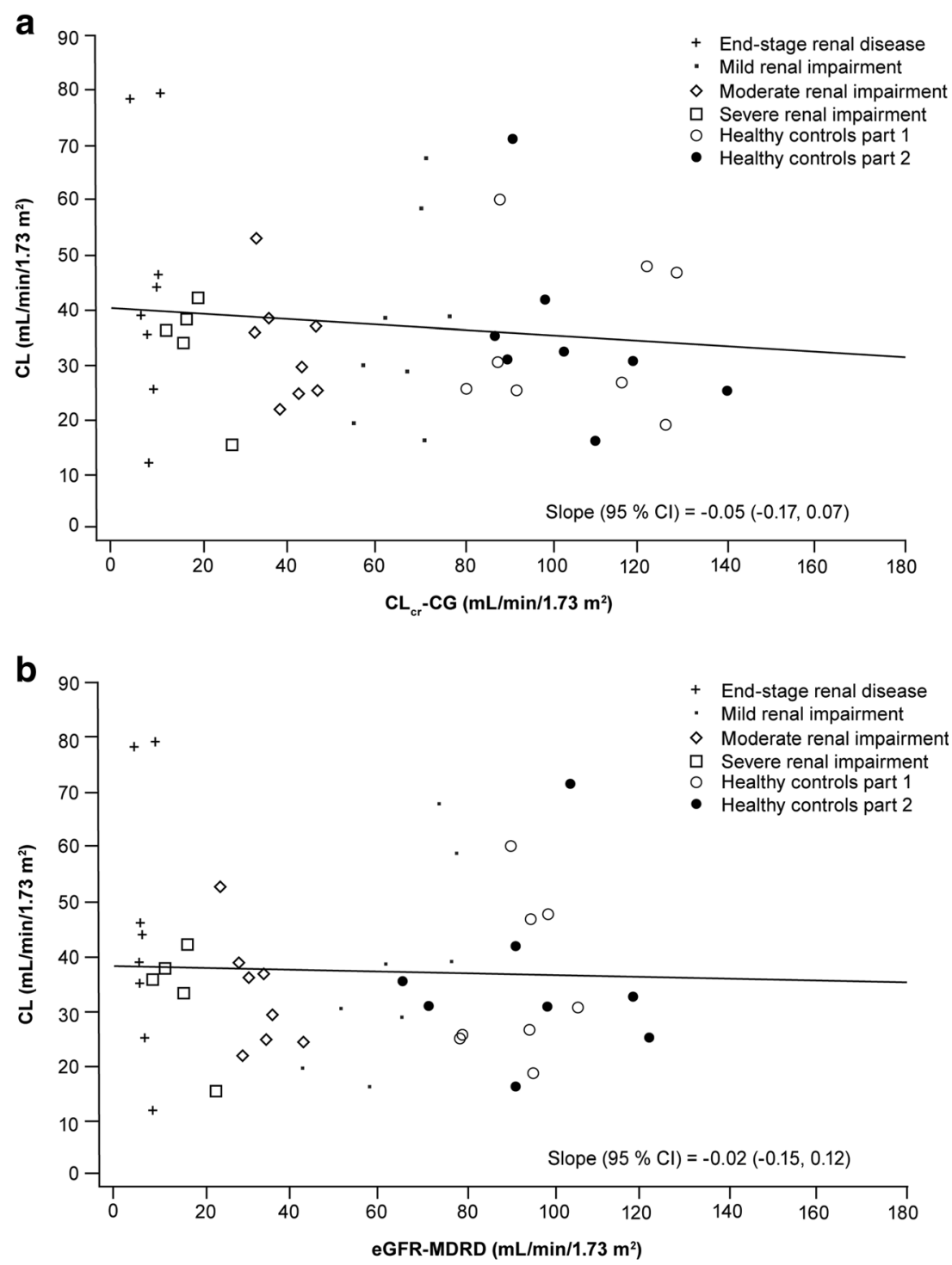

(chest discomfort) during IV administration of isavuconazole that was considered related to the study drug and led to discontinuation from the study (Table 5).

\section{Discussion}

This study showed that there was no significant impact of renal function measured by either $\mathrm{CL}_{\mathrm{cr}}$ or eGFR on isavuconazole $\mathrm{AUC}$ and $C_{\max }$ values. The $\mathrm{AUC}_{\infty}$ and $\mathrm{AUC}_{\text {last }}$ of plasma isavuconazole in participants with mild, moderate, or severe RI were not significantly different compared with healthy participants with normal renal function. The PK parameters of isavuconazole in plasma were similar between healthy participants with normal renal function and participants with mild, moderate, or severe RI.

Accurate assessment of kidney function is essential for determining appropriate drug dosing regimens [20]. Therefore,
eGFR-MDRD equations have been developed to more accurately assess renal function and renal impairment and appropriate drug dosage adjustments [20]. Historically, the CG equation was the method most commonly used to assess drug dosage adjustments in renally impaired patients in clinical practice [20]. Currently, eGFR using the MDRD approach is an alternative approach to the CG method to determine drug dosages in patients with renal impairment [20-22]. However, previous studies have shown discordance rates of up to $40 \%$ and significant difference in drug dosing regimens between the MDRD and CG methods [21, 22]. We found no significant relationship between either total plasma isavuconazole $C_{\max }$ or total body clearance from plasma and renal function assessed by $\mathrm{CL}_{\mathrm{cr}}(\mathrm{CG})$ or eGFR (MDRD). This is consistent with a population PK study which showed that eGFR used as a covariate did not have a significant effect on clearance of isavuconazole [23]. These findings add further support that dose adjustments of isavuconazole are unlikely to be required 
Table 5 Summary of treatment-emergent adverse events ${ }^{\mathrm{a}}$

\begin{tabular}{|c|c|c|c|c|c|c|}
\hline \multirow[t]{2}{*}{ Parameter $n(\%)$} & \multicolumn{2}{|l|}{ Study part 1} & \multicolumn{4}{|l|}{ Study part 2} \\
\hline & $\begin{array}{l}\text { Healthy control } \\
\text { group }(n=9)\end{array}$ & $\begin{array}{l}\text { ESRD } \\
(n=11)\end{array}$ & $\begin{array}{l}\text { Healthy control } \\
\text { group }(n=8)\end{array}$ & $\begin{array}{l}\text { Mild RI } \\
(n=8)\end{array}$ & $\begin{array}{l}\text { Moderate RI } \\
(n=8)\end{array}$ & $\begin{array}{l}\text { Severe R } \\
(n=5)\end{array}$ \\
\hline TEAEs & $7(77.8)$ & $7(63.6)$ & $4(50.0)$ & $5(62.5)$ & $5(62.5)$ & $4(80.0)$ \\
\hline Drug-related TEAEs & $7(77.8)$ & $7(63.6)$ & $4(50.0)$ & $4(50.0)$ & $5(62.5)$ & $3(60.0)$ \\
\hline TEAEs leading to study discontinuation & $1(11.1)^{\mathrm{b}}$ & 0 & 0 & 0 & 0 & 0 \\
\hline \multicolumn{7}{|l|}{ Most common TEAEs ${ }^{c}$} \\
\hline General disorders and administration site conditions & $6(66.7)$ & $4(36.4)$ & $2(25.0)$ & $2(25.0)$ & $3(37.5)$ & $3(60.0)$ \\
\hline Nervous system disorders & $3(33.3)$ & $4(36.4)$ & $2(25.0)$ & $2(25.0)$ & $4(50.0)$ & $1(20.0)$ \\
\hline Gastrointestinal disorders & 0 & $3(27.3)$ & $1(12.5)$ & $1(12.5)$ & $2(25.0)$ & $2(40.0)$ \\
\hline Infections and infestations & 0 & $2(18.2)$ & 0 & 0 & 0 & $1(20.0)$ \\
\hline Skin and subcutaneous tissue & 0 & $2(18.2)$ & $1(12.5)$ & 0 & 0 & 0 \\
\hline
\end{tabular}

ESRD end-stage renal disease, MedDRA medical dictionary for regulatory activities, $R I$ renal impairment, TEAE treatment-emergent adverse event

${ }^{\text {a }}$ By MedDRA version 12.1 system organ class

${ }^{\mathrm{b}}$ TEAE was considered to be drug-related in this patient

${ }^{\mathrm{c}}$ TEAEs occurring in $\geq 2$ patients overall

in individuals with RI or in those with ESRD who are receiving hemodialysis.

Two approaches were used in the analysis of data: The first approach examined renal function by categorically grouping the severity of impairment (mild, moderate, severe or ESRD as defined by $\mathrm{CL}_{\mathrm{cr}}$ by $\mathrm{CG}$ ), and the second approach examined renal function as a continuous variable (eGFR or $\mathrm{CL}_{\mathrm{cr}}$ ) related to PK parameters to the measure of renal function. Grouping by severity of renal impairment parallels the clinical approach found in national and international guidelines and is relevant to clinicians familiar with these guidelines [24-29]. The continuous variable approach was objective and independent of empirical classification. Consistency between the two approaches adds robustness to the findings of this study and provides support to its conclusions.

In participants with ESRD, the decrease in AUC and $C_{\max }$ and wide variability for each when dialysis preceded drug dosing were influenced by intercompartmental fluid shifts intrinsic to hemodialysis and post-dialysis recovery. The clearance of drugs by conventional hemodialysis is predominantly a passive diffusional process driven by unbound concentration gradient between plasma water and dialysate $[8,30]$. As the binding of drug to plasma proteins increases, removal of drug by dialysis will decrease [31]. Therefore, hemodialysis did not clear isavuconazole from the plasma of individuals with ESRD due to the high protein binding of isavuconazole (>99.9\%) predominantly to albumin. However, the longer half-life and volume of distribution of isavuconazole in individuals with ESRD may also be due to decreased plasma binding by albumin due to uremia which may impact drug metabolism by the liver [32]. The increase in AUC in dialysis patients may be due to the displacement of isavuconazole from albumin by heparin while patients are on dialysis which has been reported for some other drugs [33]. In view of the low and intermittent dialytic clearance of isavuconazole from plasma, it can be concluded that clearance of isavuconazole by thrice weekly dialysis is unlikely to have any appreciable effects on the PK of isavuconazole in ESRD patients. Therefore, post-dialysis supplementation of isavuconazole is unlikely to be required. Conversely, if isavuconazole is inadvertently overdosed, the overdose cannot be effectively managed by hemodialysis.

Analysis of isavuconazole PK across renal function as a continuous variable showed no significant impact of renal function measured by eGFR on $C_{\max }$ and AUC. Although differences in the renal excretion of isavuconazole were observed among groups with differing levels of renal impairment, the overall level of renal excretion was quite small and the observed differences would not be expected to impact on the PK of isavuconazole in any significant way.

In this study, a single IV infusion of isavuconazole was generally well tolerated by individuals with normal renal function; those with mild, moderate, or severe RI; and those with ESRD. The number and percentage of participants experiencing TEAEs were low and generally similar between groups, and most TEAEs were considered mild. However, more individuals in the ESRD and severe RI groups experienced gastrointestinal disorders compared with those with normal renal function. However, for those receiving hemodialysis, consideration should be given to administering isavuconazole predialysis. Based on the findings of this study, dose adjustments of isavuconazole are unlikely to be required in individuals with RI or in those with ESRD who are receiving hemodialysis. 
Acknowledgements Isavuconazonium sulfate was co-developed by Astellas Pharma Global Development, Inc., Northbrook, IL, USA, and Basilea Pharmaceutica International Ltd., Basel, Switzerland.

\section{Compliance with ethical standards}

Conflict of interest R.W. Townsend, D.L. Kowalski, S. Mujais, and A.V. Desai are all employees of Astellas Pharma Global Development, Inc. S. Akhtar was an employee of Astellas Pharma Global Development, Inc. at the time of the study. H. Alcorn and J. Berg are employees of DaVita Clinical Research who were contracted by Astellas Pharma Global Development, Inc. to perform this trial. This study was funded by Astellas Pharma Global Development, Inc. Editorial support was provided by John Clarke, Envision Pharma Group, Horsham, UK, funded by Astellas Pharma Global Development, Inc.

Open Access This article is distributed under the terms of the Creative Commons Attribution 4.0 International License (http:// creativecommons.org/licenses/by/4.0/), which permits unrestricted use, distribution, and reproduction in any medium, provided you give appropriate credit to the original author(s) and the source, provide a link to the Creative Commons license, and indicate if changes were made.

\section{References}

1. Akan H, Antia VP, Kouba M, Sinko J, Tanase AD, Vrhovac R et al (2013) Preventing invasive fungal disease in patients with haematological malignancies and the recipients of haematopoietic stem cell transplantation: practical aspects. J Antimicrob Chemother 68(Suppl 3):iii5-ii16. doi:10.1093/jac/dkt389

2. Kontoyiannis DP, Marr KA, Park BJ, Alexander BD, Anaissie EJ, Walsh TJ et al (2010) Prospective surveillance for invasive fungal infections in hematopoietic stem cell transplant recipients, 20012006: overview of the Transplant-Associated Infection Surveillance Network (TRANSNET) Database. Clin Infect Dis 50(8):1091-1100. doi:10.1086/651263

3. Marr KA, Carter RA, Crippa F, Wald A, Corey L (2002) Epidemiology and outcome of mould infections in hematopoietic stem cell transplant recipients. Clin Infect Dis 34(7):909-917. doi: $10.1086 / 339202$

4. Pagano L, Caira M, Candoni A, Offidani M, Fianchi L, Martino B et al (2006) The epidemiology of fungal infections in patients with hematologic malignancies: the SEIFEM-2004 study. Haematologica 91(8):1068-1075

5. Baddley JW, Andes DR, Marr KA, Kontoyiannis DP, Alexander BD, Kauffman CA et al (2010) Factors associated with mortality in transplant patients with invasive aspergillosis. Clin Infect Dis 50(12):1559-1567. doi:10.1086/652768

6. Vandewoude KH, Blot SI, Benoit D, Colardyn F, Vogelaers D (2004) Invasive aspergillosis in critically ill patients: attributable mortality and excesses in length of ICU stay and ventilator dependence. J Hosp Infect 56(4):269-276. doi:10.1016/j.jhin.2004.01. 006

7. Verbeeck RK, Musuamba FT (2009) Pharmacokinetics and dosage adjustment in patients with renal dysfunction. Eur J Clin Pharmacol 65(8):757-773. doi:10.1007/s00228-009-0678-8

8. Bohler J, Donauer J, Keller F (1999) Pharmacokinetic principles during continuous renal replacement therapy: drugs and dosage. Kidney Int Suppl 72:S24-S28

9. Walsh TJ, Anaissie EJ, Denning DW, Herbrecht R, Kontoyiannis DP, Marr KA et al (2008) Treatment of aspergillosis: clinical practice guidelines of the Infectious Diseases Society of America. Clin Infect Dis 46(3):327-360. doi:10.1086/525258
10. Ader F, Bienvenu AL, Rammaert B, Nseir S (2009) Management of invasive aspergillosis in patients with COPD: rational use of voriconazole. Int J Chron Obstruct Pulmon Dis 4:279-287

11. Girmenia C (2009) New generation azole antifungals in clinical investigation. Expert Opin Investig Drugs 18(9):1279-1295. doi: 10.1517/13543780903176407

12. von Mach MA, Burhenne J, Weilemann LS (2006) Accumulation of the solvent vehicle sulphobutylether beta cyclodextrin sodium in critically ill patients treated with intravenous voriconazole under renal replacement therapy. BMC Clin Pharmacol 6:6. doi:10. 1186/1472-6904-6-6

13. Janssen Pharmaceutica N.V (2001) Sporanox ${ }^{\circledR}$ (itraconazole) prescribing information. Available at: http://www.janssen.com/us/ sites/www_janssen_com_usa/files/products-documents/pisporanoxcapsules.pdf; visited 16 Feb 2017

14. Miceli MH, Kauffman CA (2015) Isavuconazole: a new broadspectrum triazole antifungal agent. Clin Infect Dis 61(10):15581565. doi:10.1093/cid/civ571

15. Seyedmousavi S, Verweij PE, Mouton JW (2015) Isavuconazole, a broad-spectrum triazole for the treatment of systemic fungal diseases. Expert Rev Anti-Infect Ther 13(1):9-27. doi:10.1586/ 14787210.2015 .990382

16. Astellas Pharma US I (2015) CRESEMBA $^{\circledR}$ (isavuconazonium sulfate) prescribing information. Available at: http://www. accessdata.fda.gov/drugsatfda_docs/label/2015/ 207500Orig1s000lbl.pdf; visited 16 Feb 2017

17. European Medicines Agency (2015) Cresemba Isavuconazole. Available at: http://www.ema.europa.eu/ema/index.jsp?curl= pages/medicines/human/medicines/002734/human_med_001907. jsp\&mid=WC0b01ac058001d124; visited 16 Feb 2017

18. US Food and Drug Administration (2010) Guidance for industry: pharmacokinetics in patients with impaired renal function - study design, data analysis, and impact on dosing and labeling. Draft guidance [revision 1]. Available at: http://www.fda.gov/ downloads/Drugs/.../Guidances/UCM204959.pdf; visited 16 Feb 2017

19. European Medicines Agency Committee for Medicinal Products for Human Use (CHMP) (2004) Note for guidance on the evaluation of the pharmacokinetics of medicinal products in patients with impaired renal function. Available at: http://www.ema.europa.eu/ docs/en_GB/document_library/Scientific_guideline/2009/09/ WC500003123.pdf; visited 9 Dec 2015

20. Nyman HA, Dowling TC, Hudson JQ, Peter WL, Joy MS, Nolin TD (2011) Comparative evaluation of the Cockcroft-Gault equation and the Modification of Diet in Renal Disease (MDRD) study equation for drug dosing: an opinion of the Nephrology Practice and Research Network of the American College of Clinical Pharmacy. Pharmacotherapy 31(11):1130-1144. doi:10.1592/phco.31.11. 1130

21. Golik MV, Lawrence KR (2008) Comparison of dosing recommendations for antimicrobial drugs based on two methods for assessing kidney function: Cockcroft-Gault and Modification of Diet in Renal Disease. Pharmacotherapy 28(9):1125-1132. doi:10.1592/phco.28. 9.1125

22. Hermsen ED, Maiefski M, Florescu MC, Qiu F, Rupp ME (2009) Comparison of the Modification of Diet in Renal Disease and Cockcroft-Gault equations for dosing antimicrobials. Pharmacotherapy 29(6):649-655. doi:10.1592/phco.29.6.649

23. Kovanda LL, Desai AV, Lu Q, Townsend RW, Akhtar S, Bonate P et al (2016) Isavuconazole population pharmacokinetic analysis using nonparametric estimation in patients with invasive fungal disease (results from the VITAL study). Antimicrob Agents Chemother 60(8):4568-4576. doi:10.1128/AAC.00514-16

24. Chertow GM, Lee J, Kuperman GJ, Burdick E, Horsky J, Seger DL et al (2001) Guided medication dosing for inpatients with renal insufficiency. JAMA 286(22):2839-2844 
25. Drenth-van Maanen AC, van Marum RJ, Jansen PA, Zwart JE, van Solinge WW, Egberts TC (2015) Adherence with dosing guideline in patients with impaired renal function at hospital discharge. PLoS One 10(6):e0128237. doi:10.1371/journal.pone.0128237

26. Munar MY, Singh H (2007) Drug dosing adjustments in patients with chronic kidney disease. Am Fam Physician 75(10):1487-1496

27. Nolin TD, Aronoff GR, Fissell WH, Jain L, Madabushi R, Reynolds K et al (2015) Pharmacokinetic assessment in patients receiving continuous RRT: perspectives from the Kidney Health Initiative. Clin J Am Soc Nephrol 10(1):159-164. doi:10.2215/ CJN.05630614

28. Swan SK, Bennett WM (1992) Drug dosing guidelines in patients with renal failure. West J Med 156(6):633-638

29. van Dijk EA, Drabbe NR, Kruijtbosch M, De Smet PA (2006) Drug dosage adjustments according to renal function at hospital discharge. Ann Pharmacother 40(7-8):1254-1260. doi:10.1345/aph. $1 \mathrm{G} 742$
30. Pea F, Viale P, Pavan F, Furlanut M (2007) Pharmacokinetic considerations for antimicrobial therapy in patients receiving renal replacement therapy. Clin Pharmacokinet 46(12):997-1038. doi:10. 2165/00003088-200746120-00003

31. Trotman RL, Williamson JC, Shoemaker DM, Salzer WL (2005) Antibiotic dosing in critically ill adult patients receiving continuous renal replacement therapy. Clin Infect Dis 41(8):1159-1166. doi:10. $1086 / 444500$

32. Nolin TD (2008) Altered nonrenal drug clearance in ESRD. Curr Opin Nephrol Hypertens 17(6):555-559. doi:10.1097/MNH. 0b013e3283136732

33. Desmond PV, Roberts RK, Wood AJ, Dunn GD, Wilkinson GR, Schenker S (1980) Effect of heparin administration on plasma binding of benzodiazepines. Br J Clin Pharmacol 9(2): $171-175$ 